\title{
Age-dependence of power spectral density and fractal dimension of bone mineralized matrix in atomic force microscope topography images: potential correlates of bone tissue age and bone fragility in female femoral neck trabeculae
}

\author{
Petar Milovanovic, ${ }^{1}$ Marija Djuric ${ }^{1}$ and Zlatko Rakocevic $^{2}$ \\ ${ }^{1}$ Laboratory for Anthropology, Institute of Anatomy, School of Medicine, University of Belgrade, Belgrade, Serbia \\ ${ }^{2}$ Laboratory for Atomic Physics, Institute of Nuclear Sciences Vinca, University of Belgrade, Belgrade, Serbia
}

\begin{abstract}
There is an increasing interest in bone nano-structure, the ultimate goal being to reveal the basis of agerelated bone fragility. In this study, power spectral density (PSD) data and fractal dimensions of the mineralized bone matrix were extracted from atomic force microscope topography images of the femoral neck trabeculae. The aim was to evaluate age-dependent differences in the mineralized matrix of human bone and to consider whether these advanced nano-descriptors might be linked to decreased bone remodeling observed by some authors and age-related decline in bone mechanical competence. The investigated bone specimens belonged to a group of young adult women ( $n=5$, age: 20-40 years) and a group of elderly women $(n=5$, age: 70 95 years) without bone diseases. PSD graphs showed the roughness density distribution in relation to spatial frequency. In all cases, there was a fairly linear decrease in magnitude of the power spectra with increasing spatial frequencies. The PSD slope was steeper in elderly individuals $(-2.374$ vs. -2.066$)$, suggesting the dominance of larger surface morphological features. Fractal dimension of the mineralized bone matrix showed a significant negative trend with advanced age, declining from 2.467 in young individuals to 2.313 in the elderly $(r=0.65, P=0.04)$. Higher fractal dimension in young women reflects domination of smaller mineral grains, which is compatible with the more freshly remodeled structure. In contrast, the surface patterns in elderly individuals were indicative of older tissue age. Lower roughness and reduced structural complexity (decreased fractal dimension) of the interfibrillar bone matrix in the elderly suggest a decline in bone toughness, which explains why aged bone is more brittle and prone to fractures.
\end{abstract}

Key words: aging; atomic force microscopy; bone fragility; bone mineralized matrix; fractal dimension; hip; power spectral density; remodeling.

\section{Introduction}

Hip fractures are a global health problem in aged populations, and current projections point to their increased prevalence in forthcoming years (Cooper et al. 1992; Burge et al. 2007). Moreover, current standard methods for assessment and understanding of the fracture risk in elderly individuals are still insufficient (Cummings, 1985; De Laet et al.

\footnotetext{
Correspondence

Marija Djuric, Laboratory for Anthropology, Institute of Anatomy, School of Medicine, University of Belgrade, 4/2 Dr Subotica, 11000 Belgrade, Serbia. T: + 381112686 172; F: +38 1112686 172;

E: marijadjuric5@gmail.com
}

Accepted for publication 26 July 2012

Article published online 5 September 2012
1997; Stone et al. 2003; Schuit et al. 2004). Therefore, apart from bone mineral density, additional bone features are increasingly appreciated as potential determinants of bone fragility. Particular emphasis has been placed on bone micro-architecture (Blain et al. 2008; Djuric et al. 2010; Boutroy et al. 2011; Milovanovic et al. 2012a; Skedros et al. 2012), cellular characteristics (Vashishth et al. 2000; McCreadie et al. 2004; Qiu et al. 2005, 2006; Busse et al. 2010; Halade et al. 2011) and compositional properties of the bone material (McCreadie et al. 2006; Roschger et al. 2007; Busse et al. 2009; Fratzl-Zelman et al. 2009, 2011; Thurner, 2009; Milovanovic et al. 2011, 2012b; Skedros et al. 2012). With regard to bone at the material level, there are an increasing number of studies dealing with bone nano-structure along with increasing interest in nano-level revelations 
of bone tissue (Hassenkam et al. 2007; Thurner, 2009). Atomic force microscopy (AFM) has been recently applied to bone specimens, allowing high-resolution imaging of bone trabeculae (Fantner et al. 2004; Hassenkam et al. 2004, 2005; Kindt et al. 2005, 2007; Thurner et al. 2005, 2007; Milovanovic et al. 2011, 2012b). In materials science, AFM images are frequently used to obtain power spectral density (PSD) graphs and/or fractal dimension (FD), providing an advanced description of surface patterns (Pfeifer, 1984; Silk et al. 1998; Ulmeanu et al. 2000; Cui et al. 2001; Dobrescu et al. 2004; Gavrila et al. 2007; Constantoudis \& Gogolides, 2008; Liu et al. 2010; Munz et al. 2011). PSD correlates the vertical amplitude with the spatial frequency of surface features, revealing characteristics of the surface structure (Mitchell \& Bonnell, 1990; Lita \& Sanchez, 2000), whereas FD measures structural complexity and surface roughness (Dougherty \& Henebry, 2001). These properties of materials have been repeatedly investigated in terms of their relation to material formation/modification processes (Pfeifer, 1984; Silk et al. 1998; Ulmeanu et al. 2000; Cui et al. 2001; Dobrescu et al. 2004; Gavrila et al. 2007; Constantoudis \& Gogolides, 2008; Liu et al. 2010; Munz et al. 2011). However, in contrast to their frequent use and relevance in materials science, those analyses have not yet been applied in AFM characterizations of bone material. Comparing the bone tissue of different ages revealed several compositional features linked to younger bone tissue age, such as lower matrix mineralization level (Grynpas, 1993; Huja et al. 2006; Busse et al. 2010), absent/barely present lacunar hypermineralization (Busse et al. 2010) and domination of smaller mineral crystals (Su et al. 2003; Kuhn et al. 2008; Milovanovic et al. 2011). All these features have been attributed to freshly remodeled bone tissue; however, the relationship between the AFM topographical patterns and the process of bone remodeling has been obscure. Furthermore, as the nano-structural determinants of bone fragility are still insufficiently understood, advanced nanoscopic analyses of bone mineralized matrix are necessary.

In this study, PSD curves and fractal dimensions of the bone mineralized matrix were extracted from AFM images of the femoral neck trabeculae in a group of young vs. elderly women. These advanced nano-morphological analyses were used to evaluate age-dependent differences of the human bone matrix, and to consider whether they might be linked to altered bone remodeling and observed agerelated decline in bone mechanical competence.

\section{Materials and methods}

\section{Selection and preparation of specimens}

Trabecular bone samples from the superolateral portion of the femoral neck were obtained from 10 women during autopsy at the Institute of Forensic Medicine, School of Medicine, University of Belgrade. The specimens belonged to five women 20-40 years old and five women 70-95 years old who did not display signs of diseases affecting the skeleton or a history of using medications that alter bone metabolism.

Bones were kept in $70 \%$ ethanol for 2 weeks, cleaned of adherent soft tissue and cut using a low-speed diamond wheel saw 650 with water soluble coolant (South Bay Technology Inc., San Clemente, CA, USA). The trabecular bone specimens were then cleaned ultrasonically in alcohol for 5 min and dried naturally at room temperature. We handled all the specimens in the same manner in order to ensure validity of inter-specimen comparisons.

\section{AFM imaging: power spectral density and fractal dimension}

Trabecular bone samples were glued onto the sample disk, and imaged by Multimode quadrex SPM with a Nanoscope Ille controller (Veeco Instruments, Inc.) under ambient conditions. The images were acquired by standard AFM tapping mode using a commercial Solid Nitride Cone AFM probe (NanoScience Instruments, Inc.: cantilever length of $125 \mu \mathrm{m}$, force constant $40 \mathrm{~N} \mathrm{~m}^{-1}$, resonant frequency $275 \mathrm{kHz}$, tip radius $<10 \mathrm{~nm}$ ). In each sample, at least 10 topography images were obtained to assure the consistency of observed features. Simultaneously with the AFM topography imaging, we performed AFM phase imaging which allowed differentiation between the materials based on their different characteristics.

Power spectral density analysis was performed on AFM topography images using the software wsxM (WSxM v5.0, developed by Horcas et al. 2007). Power spectral density represents an advanced analysis of the surface roughness (Fig. 1) based on Fourier decomposition of an image into waves of particular wavelengths, i.e. frequencies (spatial frequencies) (Mitchell \& Bonnell, 1990; Lita \& Sanchez, 2000; Nenadović et al. 2012). Briefly, in the case of AFM topography data, PSD analysis deconvolutes the roughness as a function of unit length of the surface (Nenadovic et al. 2012). Moreover, PSD analysis specifically correlates the vertical amplitude with the spatial frequency of surface features, revealing characteristics of the surface structure (Mitchell \& Bonnell, 1990; Lita \& Sanchez, 2000; Nenadović et al. 2012) and describing the contribution of various elements (features) to the surface roughness (Nenadović et al. 2012). A complete mathematical evaluation of the PSD function can be found in other studies (Fang et al. 1997; Kitching et al. 1999). Graphical presentation shows PSD $\left(\mathrm{nm}^{4}\right)$ on the logarithmic scale on the $y$-axis, while the $x$-axis is represented by the spatial frequency $(1 / \mathrm{nm})$ and is also shown on a logarithmic scale. To account for the contribution of features of various sizes to the bone surface, the power spectrum density data were extracted from the images of various sizes (from a minimum of $0.5 \times 0.5 \mu \mathrm{m}^{2}$ to a maximum of $5 \times 5 \mu^{2}$ ). The data points collected from all images belonging to an individual were then represented on a single graph showing log PSD vs. log spatial frequency of the individual. The data points were fitted linearly as previously suggested (Ulmeanu et al. 2000; Nenadović et al. 2012) and the slope of the obtained line was determined for each individual. The slope of PSD trendline was determined in this study since it has been used successfully for illustrating differences in spatial frequency distribution relatively independently on the area (Jiang et al. 2005).

Fractal dimension is a dimensionless number that describes the complexity of object's structure (Dougherty \& Henebry, 2001) and strongly corresponds to visual perception of roughness (Zawada \& Brock, 2009). It depicts how an object occupies space (Ulmeanu et al. 2000), so that more plane surfaces have FD closer to 2, while FD of more complex or craggy surfaces approaches the value of 3 

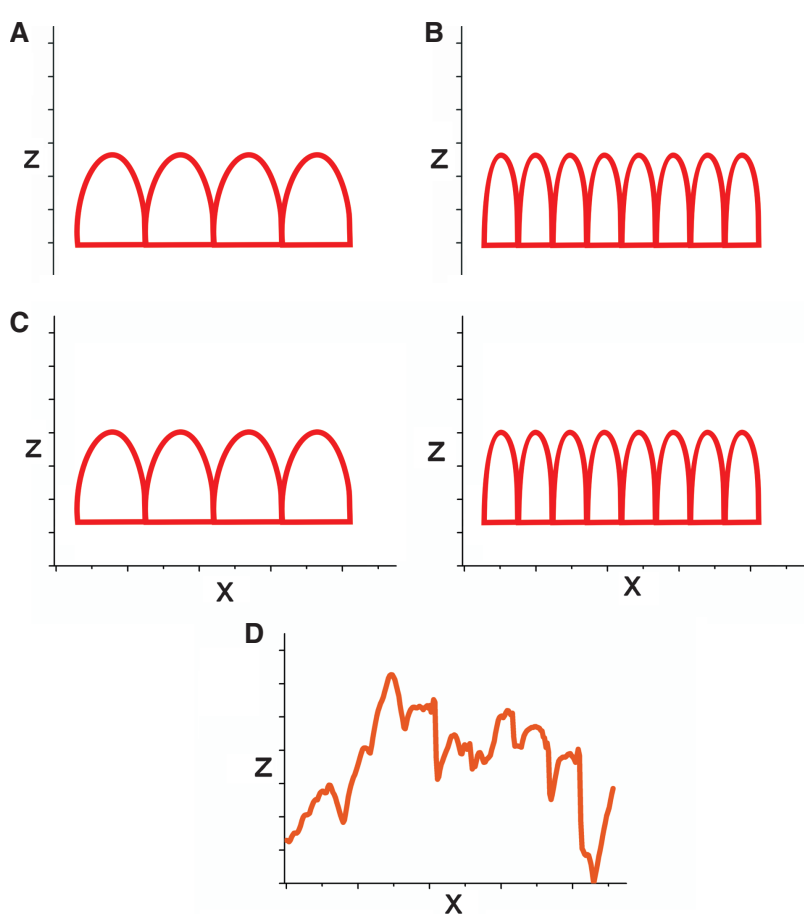

Fig. 1 Roughness analysis. (A,B) Examples of ideally regular surface profiles showing 'peaks and valleys' (2D profiles are shown for simplicity). Measures of roughness only consider the vertical (z-axis) deviation from the mean surface and therefore cannot distinguish between $A$ and $B$ profiles that display the same roughness. However, the profiles $A$ and $B$ actually differ considerably, since B has more peaks and those peaks are narrower. (C) In contrast, PSD analysis considers not only vertical deviation, but also the width (x-axis) of surface peaks ( wavelength), i.e. their number per unit length (spatial frequency = inverse wavelength). (D) A real example of a complex profile of bone surface. PSD is based on Fourier transformations which decompose the complicated wave to a number of ideal waves of particular wavelengths. For characterization of any surface, it is useful to know the vertical deviation of the peaks from the mean surface, but also the size of those elements (peaks), as well as their relative contribution (power) to overall surface topography (see Fig. 3).

(Zawada \& Brock, 2009). Moreover, fractal dimension measures the relative importance of high frequency fluctuations in surface patterns in comparison with low frequency fluctuations (Constantoudis \& Gogolides, 2008). Log PSD vs. log spatial frequency graphs provide the ability to calculate the fractal dimension of each sample according to the following equation: $\mathrm{FD}=0.5^{*}(7-\beta)$, where $\beta$ represents the absolute value of the slope of PSD trendline (Pfeifer, 1984; Silk et al. 1998).

\section{Results}

Illustrative AFM topography images of the trabeculae (Fig. 2) revealed the nano-structural features of mineralized bone matrix, showing densely packed extrafibrillar bone minerals. The representative AFM images depict the features observed consistently at various locations within investigated human trabeculae. In this study, we extracted PSD curves and fractal dimensions data from the AFM
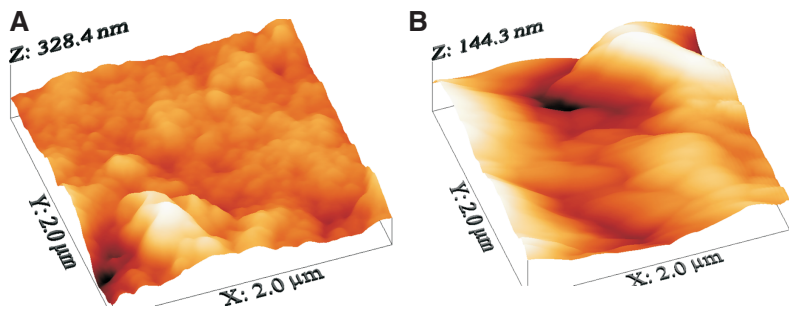

Fig. 2 Representative AFM 3D surface plot (topography images, scan dimensions: $2 \times 2 \mu \mathrm{m}^{2}$ ) of a young female $(\mathrm{A})$ and an elderly female individual (B).

topography images of the mineralized bone matrix of the femoral neck trabeculae in a group of young vs. elderly women.

Power spectral density graphs showed the roughness density distribution in relation to spatial frequency. There was a decrease in magnitude of the power spectra with increasing spatial frequencies in all cases. In each individual, the PSD data originating from AFM images of different sizes were averaged. The observed relationship between the power spectra and spatial frequency could be approximated with a straight line in each individual. Figure $3(A, B)$ shows linearly fitted PSD graphs of a young and an elderly individual, respectively. The slopes of the fitting lines were determined in both young and old individuals. The slopes showed negative values, illustrating decreased magnitudes with increasing spatial frequency. The absolute value of mean PSD slope in the elderly was higher than in the young specimens (2.374 compared with 2.066). Evaluation of the slopes of PSD trendlines in relation to age of individuals (Fig. 4) suggests a tendency towards steeper lines in the elderly. There was statistically significant dependence of PSD slope on age according to the following law: PSD $=-0.007 *$ age -1.828 $(P<0.05)$.

PSD trendlines in each individual allowed subsequent calculation of the fractal dimension of their mineralized bone matrix. Younger specimens had higher average values of fractal dimensions (2.467) than the elderly (2.313). Individual fractal dimensions are shown in Fig. 5. It was observed that the distribution of FD in young individuals was more homogeneous, and only FD in the oldest individual (38 years old) deviated towards the lower values. Elderly individuals presented with more disperse values of FD. To assess how the FD depends on the age of an individual, we have applied linear regression analysis. Evident negative correlation was found in regression analysis between FD and age, which can be expressed with the following law: $\mathrm{FD}=-0.003 *$ age $+2.586(r=0.65, P<0.05)$.

\section{Discussion}

The shape of PSD curves in materials science has been considered to reflect particular physical and chemical processes that participated in building the surface (Lita \& Sanchez, 

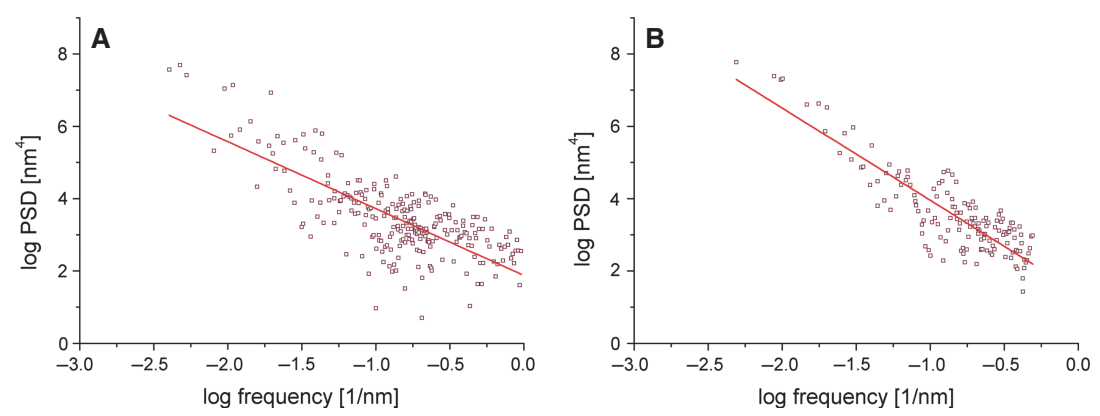

Fig. 3 Power spectral density graph with linear fitting in a young female (A) and an elderly female individual (B). Note that both axes are with a logarithmic scale. $Y$-values (PSD, power spectral density) correspond to the contribution of particular spatial frequency $X$-value to overall image.

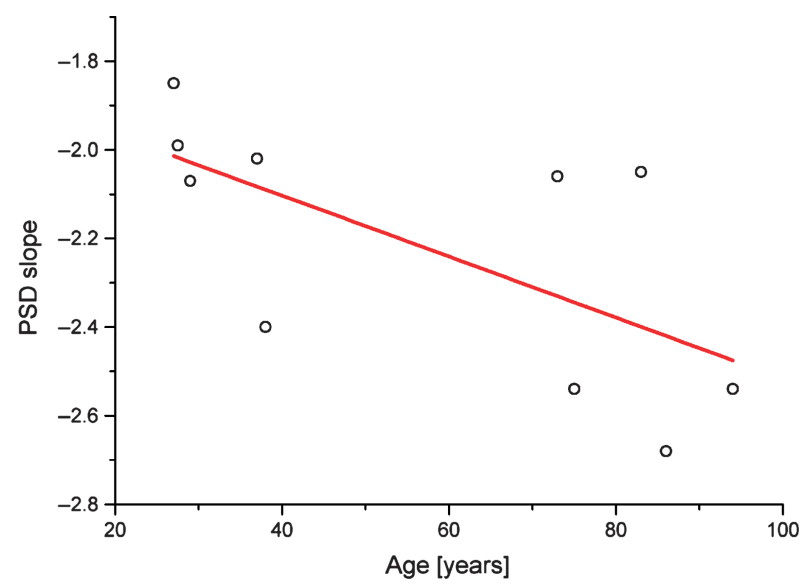

Fig. 4 Age-dependence of PSD slopes.

1999, 2000; Jiang et al. 2005; Castro et al. 2007). Such connection has not yet been evaluated in a biological context, so it remains unknown whether the surface patterns of the mineralized bone matrix may reflect the process of bone remodeling. In that context, given that the remodeling process affects bone structure by substituting old bone tissue with fresh bone tissue, AFM analyses might elucidate differential nano-structural features that are potentially attributable to different tissue age. Based on characteristics of fractal dimension reported for other systems (Dimri, 2005), our finding of higher fractal dimension of the interfibrillar surfaces in the trabecular bone of young women suggests a greater degree of roughness and more structural complexity. Moreover, it was reported that a large fractal dimension indicates the significant contribution of high-frequency (i.e. small-wavelength) fluctuations in the surface patterns (Constantoudis \& Gogolides, 2008). Such frequent spatial fluctuations may correspond to previously shown smaller mineral grains that dominate trabecular bone structure in younger individuals (Milovanovic et al. 2011). Since smaller mineral grains indicate the presence of younger bone (Su et al. 2003; Milovanovic et al. 2011), a higher fractal dimension of the bone matrix may correlate with a more recently remodeled structure.

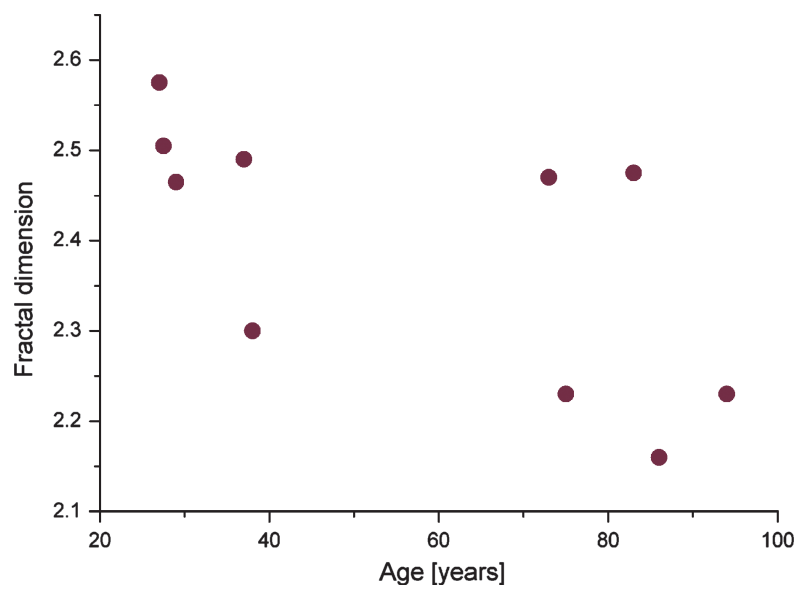

Fig. 5 Age-distribution of fractal dimension of the bone mineralized matrix in the femoral neck trabeculae.

Steeper PSD slope with decreased fractal dimension in the elderly denote the dominance of large-dimension (low spatial frequency) surface patterns. These large morphological features of the mineralized bone matrix surface may reflect the larger dimensions of the interfibrillar mineral grains observed in the previous AFM study (Milovanovic et al. 2011). In contrast to small mineral grains, the larger crystals denote older unremodeled areas of bone. Bone remodeling is a key process in bone tissue, consisting of coupled and balanced bone resorption and bone formation phases (Parfitt, 1987, 2004; Martin, 2000; Burr, 2002; Busse et al. 2010). Several studies pointed out that the bone remodeling process might be hampered in aged human bone, causing accumulation of microcracks and hypermineralized lacunae, as well an increase in tissue age (Schaffler et al. 1995; Noble, 2003; Norman et al. 2008; Busse et al. 2010). Without remodeling, senescing bone mineral would remain 'in place' long enough to undergo energy-driven physiochemical processes leading to increased size and perfection of the mineral crystals, which was observed in the trabeculae of the elderly (Paschalis et al. 1997; Milovanovic et al. 2011). As these crystals grow, they reprecipitate in a dynamic equilibrium during which the mineral 
structure becomes more ordered and the interfibrillar surface less complex, decreasing the fractal dimension in the elderly.

The present findings have particular mechanical implications. Detection of only mineralized fibrils on the fracture surfaces led to the assumption that the mineral-mineral interface is the weakest link in bone (Fantner et al. 2006) and that bone cracks within interfibrillar space (Fantner et al. 2005, 2006; Ebacher et al. 2012). Many failure modes and energy dissipation mechanisms are based on the separation of mineralized fibrils (Fantner et al. 2005; Gupta et al. 2005). Increased roughness and greater topographical complexity of interfibrillar matrix that we observed in young trabeculae would increase the interface available for cracking between the mineralized fibrils. In that way, increasing amounts of energy can be dissipated at the nano-level during the loading. Moreover, the presence of many grain boundaries in such a material might interact with crack propagation, interrupting it and/or increasing the tortuosity of the crack path. Overall, both mechanisms lead to increased bone toughness, where local nano-level failures can be regarded as a means of energy dissipation, with the ultimate goal being to prevent a macroscopic bone failure (Ritchie, 2011). In addition, since it has been suggested that nanogranular friction between mineral particles increases yield resistance (Tai et al. 2006), higher surface roughness of the mineralized fibrils would have further positive effects on bone strength. In sharp contrast to the young individuals, lower surface roughness and reduced topographical complexity (decreased FD) in the elderly signify a decline in bone toughness, which renders their bone brittle and more susceptible to fracture. Reduced toughness is also the result of changes in collagen cross-linking in aged cohorts (Viguet-Carrin et al. 2006; Barth et al. 2010). Given that bone resistance to fracture originates from various features at all levels of bone hierarchical organization (Busse et al. 2010; Launey et al. 2010; Ritchie, 2011; Milovanovic et al. 2012a), it is important to try to extract the individual contributions of each feature to overall bone strength. In that context, our AFM study showed the particular contributions of the mineralized bone matrix from the morphological point of view. However, further experimental studies are necessary to provide direct demonstration of mechanical behavior at the interfibrillar level.

Additional studies are warranted to determine how the age-related changes in PSD and FD shown in the present study might interact with larger scale characteristics of tissue organization. For example, it would be important to determine how these nano-scale parameters might correlate with trabecular bone packets (Parfitt, 1979), which are an important toughening mechanism in trabecular bone because they create interfaces and potentially increase mineral heterogeneity as a consequence of differences in their mean tissue age (Roschger et al. 2008; Busse et al. 2009; Ciarelli et al. 2009; Smith et al. 2010).
In addition, the PSD curve presented as a straight line with a constant slope in both age groups of individuals indeed resembles the shape of PSD curve of a randomly rough surface with self-affine characteristics, which implies that vertical and lateral surface elements vary in a constant manner (Buchko, 1997; Cui et al. 2001). The constant slope appearance is a property of fractal objects (Cui et al. 2001; Dobrescu et al. 2004). Therefore, our data suggest fractality of mineralized bone matrix, albeit limited to the investigated range of spatial frequencies at nano-scale due to the complex hierarchical organization of bone (Currey, 2012).

\section{Concluding remarks}

Our findings add new evidence for age-related differences at the level of mineralized bone matrix. Analyses of AFMderived power spectral density and fractal dimension at the nanometer scale may be useful for explaining differential bone fragility across age, and how their specific patterns may potentially correlate with bone tissue age. Lower structural complexity and surface roughness of the interfibrillar area in elderly individuals, which was reflected in decreased fractal dimension, may suggest a decline in the bone toughening mechanism, which may in turn lead to increased bone fragility in aged cohorts.

\section{Acknowledgements}

The authors thank the Ministry of Science of the Republic of Serbia, Project number: 45005.

\section{Author contributions}

Design of the study: P.M., M.D. and Z.R. AFM and PSD/FD analyses: Z.R. and P.M. Interpretation of the results and discussion of findings: P.M., M.D. and Z.R.; P.M. and M.D. wrote the paper and P.M., M.D. and Z.R. critically revised it.

\section{References}

Barth HD, Launey ME, MacDowell AA, et al. (2010) On the effect of X-ray irradiation on the deformation and fracture behavior of human cortical bone. Bone 46, 1475-1485.

Blain H, Chavassieux P, Portero-Muzy N, et al. (2008) Cortical and trabecular bone distribution in the femoral neck in osteoporosis and osteoarthritis. Bone 43, 862-868.

Boutroy S, Vilayphiou N, Roux J-P, et al. (2011) Comparison of 2D and 3D bone microarchitecture evaluation at the femoral neck, among postmenopausal women with hip fracture or hip osteoarthritis. Bone 49, 1055-1061.

Buchko CJ (1997) Processing and characterization of protein polymer thin films for surface modification of neural prosthetic devices. PhD thesis, Michigan: University of Michigan.

Burge R, Dawson-Hughes B, Solomon DH, et al. (2007) Incidence and economic burden of osteoporosis-related fractures in the United States, 2005-2025. J Bone Miner Res 22, 465-475. 
Burr DB (2002) Targeted and nontargeted remodeling. Bone 30, 2-4.

Busse B, Hahn M, Soltau M, et al. (2009) Increased calcium content and inhomogeneity of mineralization render bone toughness in osteoporosis: mineralization, morphology and biomechanics of human single trabeculae. Bone 45, 1034-1043.

Busse B, Djonic D, Milovanovic P, et al. (2010) Decrease in the osteocyte lacunar density accompanied by hypermineralized lacunar occlusion reveals failure and delay of remodeling in aged human bone. Aging Cell 9, 1065-1075.

Castro FA, Graeff CFO, Heier J, et al. (2007) Interface morphology snapshots of vertically segregated thin films of semiconducting polymer/polystyrene blends. Polymer 48, 2380-2386.

Ciarelli TE, Tjhia C, Rao DS, et al. (2009) Trabecular packet-leve lamellar density patterns differ by fracture status and bone formation rate in white females. Bone 45, 903-908.

Constantoudis V, Gogolides E (2008) Fractal dimension of line width roughness and its effects on transistor performance. In: Metrology, Inspection, and Process Control for Microlithography XXII. (eds Allgair JA, Raymond CJ), pp. 692223-10, San Jose, CA: SPIE.

Cooper C, Campion G, Melton LJ (1992) Hip fractures in the elderly: a world-wide projection. Osteoporos Int 2, 285-289.

Cui X, Hetke JF, Wiler JA, et al. (2001) Electrochemical deposition and characterization of conducting polymer polypyrrole/ PSS on multichannel neural probes. Sensor Actuat A: Phys 93, 8-18.

Cummings SR (1985) Are patients with hip fractures more osteoporotic? Review of the evidence. Am J Med 78, 487-494.

Currey J (2012) The structure and mechanics of bone. J Mater Sci 47, 41-54.

De Laet CE, van Hout BA, Burger H, et al. (1997) Bone density and risk of hip fracture in men and women: cross sectional analysis. BMJ 315, 221-225.

Dimri V (2005) Fractal Behaviour of the Earth System. Heidelberg: Springer-Verlag.

Djuric M, Djonic D, Milovanovic P, et al. (2010) Region-specific sex-dependent pattern of age-related changes of proximal femoral cancellous bone and its implications on differential bone fragility. Calcif Tissue Int 86, 192-201.

Dobrescu G, Crişan M, Zaharescu M, et al. (2004) Fractal dimension determination of sol-gel powders using transmission electron microscopy images. Mater Chem Phys 87, 184-189.

Dougherty G, Henebry GM (2001) Fractal signature and lacunarity in the measurement of the texture of trabecular bone in clinical CT images. Med Eng Phys 23, 369-380.

Ebacher V, Guy P, Oxland TR, et al. (2012) Sub-lamellar microcracking and roles of canaliculi in human cortical bone. Acta Biomater 8, 1093-1100.

Fang SJ, Haplepete S, Chen W, et al. (1997) Analyzing atomic force microscopy images using spectral methods. J Appl Phys 82, 5891-5898.

Fantner GE, Birkedal H, Kindt JH, et al. (2004) Influence of the degradation of the organic matrix on the microscopic fracture behavior of trabecular bone. Bone 35, 1013-1022.

Fantner G, Hassenkam T, Kindt JH, et al. (2005) Sacrificial bonds and hidden length dissipate energy as mineralized fibrils separate during bone fracture. Nat Mater 4, 612 .

Fantner GE, Rabinovych O, Schitter G, et al. (2006) Hierarchical interconnections in the nano-composite material bone: fibrillar cross-links resist fracture on several length scales. Compos Sci Technol 66, 1202-1208.
Fratzl-Zelman N, Roschger P, Gourrier A, et al. (2009) Combination of nanoindentation and quantitative backscattered electron imaging revealed altered bone material properties associated with femoral neck fragility. Calcif Tissue Int 85, 335-343.

Fratzl-Zelman N, Roschger P, Misof B, et al. (2011) Fragility fractures in men with idiopathic osteoporosis are associated with undermineralization of the bone matrix without evidence of increased bone turnover. Calcif Tissue Int 88, 378-387.

Gavrila R, Dinescu A, Mardare D (2007) A power spectral density study of thin films morphology based on AFM profiling. Rom J Inform Sci Technol 10, 291-300.

Grynpas M (1993) Age and disease-related changes in the mineral of bone. Calcif Tissue Int 53, S57-S64.

Gupta HS, Wagermaier W, Zickler GA, et al. (2005) Nanoscale deformation mechanisms in bone. Nano Lett 5, 2108-2111.

Halade GV, El Jamali A, Williams PJ, et al. (2011) Obesity-mediated inflammatory microenvironment stimulates osteoclastogenesis and bone loss in mice. Exp Gerontol 46, 43-52.

Hassenkam T, Fantner GE, Cutroni JA, et al. (2004) High-resolution AFM imaging of intact and fractured trabecular bone. Bone 35 , 4-10.

Hassenkam T, Jørgensen HL, Pedersen MB, et al. (2005) Atomic force microscopy on human trabecular bone from an old woman with osteoporotic fractures. Micron 36, 681-687.

Hassenkam T, Svensson RB, Zalkovskij M (2007) Nano-science revelations in bone research. Curr Nanosci 3, 345-351.

Horcas I, Fernandez R, Gomez-Rodriguez JM, et al. (2007) WSXM: a software for scanning probe microscopy and a tool for nanotechnology. Rev Sci Instrum 78, 013705-013708.

Huja S, Beck F, Thurman D (2006) Indentation properties of young and old osteons. Calcif Tissue Int 78, 392-397.

Jiang T, Hall N, Ho A, et al. (2005) Quantitative analysis of electrodeposited tin film morphologies by atomic force microscopy. Thin Solid Films 471, 76-85.

Kindt JH, Fantner GE, Thurner PJ, et al. (2005) A new technique for imaging mineralized fibrils on bovine trabecular bone fracture surfaces by atomic force microscopy. Mater Res Soc Symp Proc 874, 59-65.

Kindt JH, Thurner PJ, Lauer ME, et al. (2007) In situ observation of fluoride-ion-induced hydroxyapatite-collagen detachment on bone fracture surfaces by atomic force microscopy. Nanotechnology 18, 135102.

Kitching S, Williams PM, Roberts CJ, et al. (1999) Quantifying surface topography and scanning probe image reconstruction. J Vac Sci Technol, B 17, 273-279.

Kuhn L, Grynpas M, Rey C, et al. (2008) A comparison of the physical and chemical differences between cancellous and cortical bovine bone mineral at two ages. Calcif Tissue Int 83, 146-154.

Launey ME, Buehler MJ, Ritchie RO (2010) On the mechanistic origins of toughness in bone. Annu Rev Mater Res 40, 25-53.

Lita AE, Sanchez JJE (1999) Characterization of surface structure in sputtered Al films: correlation to microstructure evolution. $J$ Appl Phys 85, 876-882.

Lita AE, Sanchez JE Jr (2000) Effects of grain growth on dynamic surface scaling during the deposition of Al polycrystalline thin films. Phys Rev B 61, 7692-7699.

Liu F, Li C, Zhu M, et al. (2010) Kinetic roughening and mound surface growth in microcrystalline silicon thin films. Phys Status Solidi C 7, 533-536. 
Martin RB (2000) Toward a unifying theory of bone remodeling. Bone 26, 1-6.

McCreadie BR, Hollister SJ, Schaffler MB, et al. (2004) Osteocyte lacuna size and shape in women with and without osteoporotic fracture. J Biomech 37, 563-572.

McCreadie BR, Morris MD, Chen T-c, et al. (2006) Bone tissue compositional differences in women with and without osteoporotic fracture. Bone 39, 1190-1195.

Milovanovic P, Potocnik J, Stoiljkovic M, et al. (2011) Nanostructure and mineral composition of trabecular bone in the lateral femoral neck: implications for bone fragility in elderly women. Acta Biomater 7, 3446-3451.

Milovanovic P, Djonic D, Marshall RP, et al. (2012a) Microstructural basis for particular vulnerability of the superolateral neck trabecular bone in the postmenopausal women with hip fractures. Bone 50, 63-68.

Milovanovic P, Potocnik J, Djonic D, et al. (2012b) Age-related deterioration in trabecular bone mechanical properties at material level: nanoindentation study of the femoral neck in women by using AFM. Exp Gerontol 47, 154-159.

Mitchell MW, Bonnell DA (1990) Quantitative topographic analysis of fractal surfaces by scanning tunneling microscopy. J Mater Res 5, 2244-2254.

Munz M, Kim J-H, Krause O, et al. (2011) Imaging surfaces of nano-scale roughness by atomic force microscopy with carbon nanotubes as tips: a comparative study. Surf Interface Anal $\mathbf{4 3}$, 1382-1391.

Nenadović M, Potočnik J, Ristić M, et al. (2012) Surface modification of polyethylene by $\mathrm{Ag}^{+}$and $\mathrm{Au}^{+}$ion implantation observed by phase imaging atomic force microscopy. Surf Coat Technol 206, 4242-4248.

Noble B (2003) Bone microdamage and cell apoptosis. Eur Cell Mater, 6, 46-55.

Norman TL, Little TM, Yeni YN (2008) Age-related changes in porosity and mineralization and in-service damage accumulation. J Biomech 41, 2868-2873.

Parfitt AM (1979) Quantum concept of bone remodeling and turnover: implications for the pathogenesis of osteoporosis. Calcif Tissue Int 28, 1-5.

Parfitt AM (1987) Bone remodeling and bone loss: understanding the pathophysiology of osteoporosis. Clin Obstet Gynecol 30, 789-811.

Parfitt AM (2004) What is the normal rate of bone remodeling? Bone 35, 1-3.

Paschalis EP, Betts F, DiCarlo E, et al. (1997) FTIR microspectroscopic analysis of normal human cortical and trabecular bone. Calcif Tissue Int 61, 480-486.

Pfeifer P (1984) Fractal dimension as working tool for surfaceroughness problems. App/ Surface Sci 18, 146-164.

Qiu S, Sudhaker Rao D, Fyhrie DP, et al. (2005) The morphological association between microcracks and osteocyte lacunae in human cortical bone. Bone 37, 10-15.

Qiu S, Rao DS, Palnitkar S, et al. (2006) Differences in osteocyte and lacunar density between Black and White American women. Bone 38, 130-135.
Ritchie RO (2011) The conflicts between strength and toughness. Nat Mater 10, 817-822.

Roschger P, Dempster DW, Zhou H, et al. (2007) New observations on bone quality in mild primary hyperparathyroidism as determined by quantitative backscattered electron imaging. $J$ Bone Miner Res 22, 717-723.

Roschger P, Paschalis EP, Fratzl P, et al. (2008) Bone mineralization density distribution in health and disease. Bone 42, 456-466.

Schaffler MB, Choi K, Milgrom C (1995) Aging and matrix microdamage accumulation in human compact bone. Bone 17, 521-525.

Schuit SC, van der Klift M, Weel AE, et al. (2004) Fracture incidence and association with bone mineral density in elderly men and women: the Rotterdam Study. Bone 34, 195-202.

Silk T, Hong Q, Tamm J, et al. (1998) AFM studies of polypyrrole film surface morphology II. Roughness characterization by the fractal dimension analysis. Synth Metals 93, 65-71.

Skedros JG, Knight AN, Farnsworth RW, et al. (2012) Do regional modifications in tissue mineral content and microscopic mineralization heterogeneity adapt trabecular bone tracts for habitual bending? Analysis in the context of trabecular architecture of deer calcanei. J Anat 220, 242-255.

Smith L, Schirer JP, Fazzalari NL (2010) The role of mineral content in determining the micromechanical properties of discrete trabecular bone remodeling packets. J Biomech 43, 3144-3149.

Stone KL, Seeley DG, Lui LY, et al. (2003) BMD at multiple sites and risk of fracture of multiple types: long-term results from the study of osteoporotic fractures. I Bone Miner Res 18, 1947-1954.

Su X, Sun K, Cui FZ, et al. (2003) Organization of apatite crystals in human woven bone. Bone 32, 150-162.

Tai K, Ulm F-J, Ortiz C (2006) Nanogranular origins of the strength of bone. Nano Lett 6, 2520-2525.

Thurner PJ (2009) Atomic force microscopy and indentation force measurement of bone. Wiley Interdiscip Rev Nanomed Nanobiotechnol 1, 624-649.

Thurner PJ, Müller R, Kindt JH, et al. (2005) Novel techniques for high-resolution functional imaging of trabecular bone. In Proceedings of the SPIE, pp. 515-526.

Thurner PJ, Oroudjev E, Jungmann R, et al. (2007) Imaging of bone ultrastructure using atomic force microscopy. In: Modern Research and Educational Topics in Microscopy. (eds MéndezVilas A, Díaz J), pp. 37-48, Badajoz: Formatex.

Ulmeanu M, Serghei A, Mihailescu IN, et al. (2000) C-Ni amorphous multilayers studied by atomic force microscopy. Appl Surface Sci 165, 109-115.

Vashishth D, Koontz J, Qiu SJ, et al. (2000) In vivo diffuse damage in human vertebral trabecular bone. Bone 26, 147-152.

Viguet-Carrin S, Garnero P, Delmas P (2006) The role of collagen in bone strength. Osteoporos Int 17, 319-336.

Zawada DG, Brock JC (2009) A multiscale analysis of coral reef topographic complexity using lidar-derived bathymetry. J Coast Res 53, 6-15. 